\title{
Dilemas en el Grupo Andino
}

PHAXcisco ORREGo Vicus̃, abognodo chilcno, micmbro del Instituto Interamericano de Estudios Juridicos Internacionales y desde 1965 dscsor Especia! de! Departamento de Asuntos Juridicos de la OEı. Es nutor, entre otras publimainnes, de La Inlegracion Politicn (agtib); De'celopments in the Latin American Fre Trade Assuciation

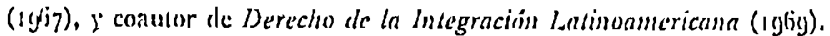
Profesor de ln Academia de Derecho Internacional de La Haya ea la primera scsión exicrna para América Latima (Bogotá, 196̆g).

Descle que la Declaración de Bogotá fuera firmada en agosto de 1966 transcurricron virtualmente tres años hasta que sus aspiraciones pudieran concretarse parcialmente en el Acuerdo Subregional suscrito en la capital de Colombia el 26 de majo último. De esta manera el proceso sc transformó en la seric de negociaciones más largas y complicadas que registra la historia de la integración cconómica en América Latina, con la particularidad de que en ellas han intervenido desde técnicos hasta ministros $y$ desde representantes del scctor privado hasta presidentes, tanto en el ámbito de la subregión como en el de la alalc. Esta situación obliga a plantcarse la interrogantc de cuáles son los dilemas con que se encuentra el Grupo Andino, tanto ell su proyeccion interna como externa, $y$ de cómo estos dilemas pueden afectar eventualmente, la marcha de la integración subregional.

El primer hecho que es necesario destacar es el relativo a las diferentes reacciones $y$ estrategias que ha suscitado el estancamiento de la didic. Este proceso de inlegración, luego de cinco años de funcionamicnto relativamente eficientc - medido en términos de aumentar los niveles de comercio intrazona! - comenzó a cntrar en una lase de visible estagnamiento cuya manifestación más palpable pucde apreciarse en las todavia inconclusas negociaciones para dar cumplimiento a la segunda fase de la Lista Común; a cstas aituras el estagnamiento reviste las caracteristicas de crisis, aun cuando la Asociación laya logrado dar cumplimicnto a algunos de sus objetivos por medio de otros mecanismos de que dispone. 
Frente a csta realidad se procuró encontrar una solución por la via de las decisiones politicas en e! marco de la propia AldLc, proceso que se inicia con la Carta que el Presidente Frci dirigicra en 1965 a los señores Herrcra, Mayobre, Prebisch y Sanz de Santa Maria solicitándoles proposiciones concretas para el perfeccionamiento de la ALALC; continúa con los documentos que ellos entregaron como respuesta -Documenlo de los Cuatro y Documenlo de la CEPAL-'; se proyecta en la Reunión de Ministros de Relaciones Exteriores de los paises de la alalc, celebrada en Nontevidco en noviembre de 1965 , y en la institucionalización del Conscjo de Ministros como órgano superior de la $\Lambda \mathrm{LALG}^{2} ;$ y culmina con la Declaración de los Presidentes en abril de 1967 . A través de este proceso se esbozan los mecanismos que habrian de conducir a la superación de las dificultades, principalmente la desgravación automática, un amplio:margen preferencial, la tarifa exterior común, la coordinación de politicas cconómicns, los reajustes institucionales $y$, en definitiva, el establecimiento de un mercado común verdaderamente "bolivariano" que abarcara a todos los paises latinoamericanos mediante la convergencia de la ALALC y el Mercado Común Centroamericano y la asociación de los paises no miembros te ninguno de ellos.

Sin embargo, a corto andar se comprobaria que todo este esfuerzo habia resultado dramáticamente formalista y que ninguno de los objetivos propuestos podrian alcanzarse a corto plazo $y$, lo que es peor todavia, tampoco cxistia la intención de alcanzarlos en cuanto se refiere a reorientar las políticas nacionales hacia la consecución de tales objetivos, con lo cual todo el edificio proyectado carecia de cimientos. De esta manera rcsultó que el problema de la aldice continuaba sin solución y que se había vuelto al mismo punto de partida, con el agravante de que se habian

1Tanto la Carta del Presidente Frei como cl Documento de los Cuatro fueron publicados en

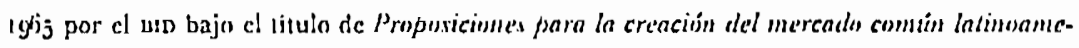
ricano. El Documento de cerse lleva pur titulo Combribución a la politicn de integración

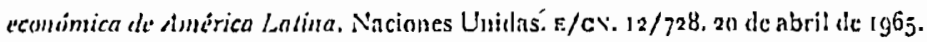

${ }^{2}$ El Protocoles que institucionaliza al Consejo de Xinistros fue firmado el 12 de diciembre de ı g66, a excepción de Chile que sỏlo lo hizo en abri! de :g67. Este instrumento todavia no há entrado en vigor pero el Conscjo funciona provisionalmente como conferencia cxtraordinaria. 
ESTUDIOS INTER N A C:ONA LE S

creado lascinantes expectativas, dentro y fuera de Amćrica Latina, que terminarian en un sentimiento de frustración bastante gencralizado complicando sobremanera el ambiente psicológico sobre el cual habrian de ensayarse otras soluciones.

\section{Estralegias allernativas}

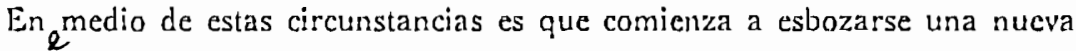
serie de soluciones, esta vez aparentemente más cercanas a las realidades politicas que eslán dispuestos a aceptar sus respectivos partidarios. Un tipo de solución que ya se encuentra más definido es el de los acúerdos subregionales, que procurarian acelerar entre los paises participantes el proceso de integración de tal manera de llegar a constituir una unidad económica más viable y competitiva ${ }^{3}$. El otro tipo de solución seria casi diametralmente opuesto $y$, si bien todavia. no sc encuentra planteado en términos explicitos $y$ definidos, ya pueden deducirse sus principales implicaciones: se trataria de transformar a la Alalc en un mecanismo preferencial multilateral sin aspiraciones de llegar a una zona de libre comercio como la que prevé el Tratado de Montevideo $y$, mucho menos, a una unión aduanera o a un mercado común; ello implicaria rcformar el Tratado de Montevideo, abandonando por ahora sus ya modestos objetivos, los que podrian retomarse en un futuro no determinado, abandonar sus principales mecanismos, comenzando por el de la Lista Común, y, en definitiva, implicaria retrotraerse al año 1960 reviviendo en forma multilateral los arreglos preferenciales que entonces existieron en el cono sur, los cuales comenzarian a operar sobre la base del mayor comercio reciproco que generó el Tratado de Montevideo. Está última solución seria presuntamente propiciada por Argentina, Brasil y'México, paises que en gencral se opondrian a los intenlos de integración acclerada y a las iniciativas de tipo supranacional, a la vez que condicionarián la integración regional a la previa integración nacionalt. La primera solu-

${ }^{3}$ El régimen de ios acuerdos subregionales en el marco de la Alatce fuc fijado por la Resolucionn 202 del Conscjo de . Ministros y desarrollacks por la Resslución 222 de la Conferencia y its del Comité Ejecutivo. Las bases generales del Acuerdo Subregional de la Declaración de Bogotá fueron aprobadas por la Resoluciin 203 del Consejo de $\lambda$ Linistros.

"Véanse las criticas formuladas a esta tesis por Raúl Prebisch en sus articulos publicatos

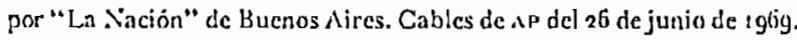


Franciscu Orrego / Dilemas ell el Grupo Andino

ción, en cambio, es la propiciada por los paises que suscribieron el Acucrdo Subregional Andino; cn todo caso, y por las razones que se anotarán más adelante, esta respectiva toma de posiciones debe considerarse con bencficio de inventarios.

Es muy posible que estas diferentes estrategias sc aclaren un tanto en el curso de las reuniones de cualuación que la ALAl.c ha convocado para los próximos meses en Montevideo, con el fin de apreciar cuáles han sido los rcsultados del proceso y los caminos a seguir en el futuro; en todo caso scrá menestcr analizar lo que alli sc diga leyendo entre lineas, pues es presumible que ningún gobierno querrá cargar con el peso politico de contradecir públicamente lo proclamado por la Declaración de los Presidentes, hace sólo dos años. Tal es por lo menos la experiencia que sc deriva después de la segunda reunión del Consejo de Ministros de la ALALc, celebrada en Asunciốn en septiembre de 1967 , en la cual no hubo acuerdo para instrumentar ninguna de las decisiones presidenciales respecto de la Asociación - salvo el caso de los acucrdos subregionales-, limitándose las resoluciones a encomendar diversos estudios adicionales al Comité Ejccutivo $y$ sin que las respectivas posiciones gubernamentales trascendieran con claridad a la opinión pública regional. Cabe asimismo presumir que las dos estratcgias planteadas no sc considerarán al final de cuentas como contradictorias por sus respectivos partidarios, csto es, que los acuerdos subregionales podrán seguir su curso en medio de una zona preferencial que comprenda a los restantes paises.

\section{El dilema de los paises de menor desarrollo}

El problema planteado por estas diferentes estrategias tiene algunas implicancias sumamente complejas para los partidarios de la tesis subregional. En primer lugar ya se advicrte claramente que se someterá a prueba la solidaridad de la subregión andina, en términos económicos y poli-

5 Asi por ejemplo, Venczucla propició originalmente la tesis subregional pero luego de

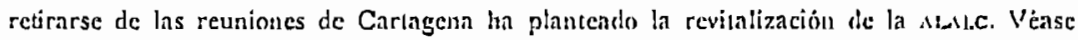
"The Economist", 28 de marzo de 1969 . Por su parte el P'crú, sigualario (lel Acuerdo Subregional, parece inclinarse. cn el ámbito de la . Asu.c por ln iesis preferencial y la supresión de ln Lista Común. Véase Exposición del Embajalor \$ax de la Fuctuc. INTaL. Holetin de la integraciön. Febrero de 1969 . 
- E S T U D I O S I N TER NACIONALES

ticos. Anteriormente se indicó que el esquema de regresar al régimen preferencial aprovecharía algunas de las bases que scntó el Tratado de Montevideo, una de las cuales seria el tratamiento más favorable a los países de menor desarrollo económico relativo de la región. Casi con seguridad pucde afirmarse que los partidarios de esta tesis plantearán como instrumento complementario de la misma el otorgar acceso preferencial a sus mercados a los productos de los paises de menor desarrollo, fundándose en razones de justicia económica pero, por sobre todo, en razones de elcmental estrategia política que permitan asegurar un apoyo suficiente en la ALALC para dicha tesis y pueda plantearse asi como posición mayoritaria. Dentro de esta perspectiva tampoco debe pasar inadvertida la gravitación favorable que pudiera tener el interés de los paises centroamericanos que, como se sabe, desde hace tiempo vienen reclamando csc acceso preferencial al mercado de la Alazc y muy particularmente al mercado mexicano. De ahi que México presentara hace algún tiempo una proposición a la ALALC destinada a otorgar ese acceso a su mercado a los paiscs centroamericanos, lo que se extendería a los demás paises de menor desarrollo de la ALALC, y tambièn los restantes paises de la ALAlc garantizarian similar acceso, proposición que fue recogida por la Declaración de los Presidentes.

Pero bien conocido es el hecho de que todas estas concesiones llevan su contrapartida: el interés de México de penetrar industrialmente en el mercado centroamericano ha sido notorio en los últimos años, debiendo igualmente recordarse que el origen primero del Grupo Andino estuvo fundamentado en similares intenciones pues se planteó como una "Comunidad Económica Caribe-Andina" que comprenderia la Gran Colombiá -cxcluyendo por tanto a Clille-, ${ }^{7}$ Centroamérica y el Gari-

- Esta proposicioin se encuentra en estudio por parie de la sLale; ha sido objeto de dos resoluciones por parie del Consejo de . Vinistros: la resolucion $168 \mathrm{y}: 96$. La Declaración de los Presidenues la recoge en su Capitulo I, $n^{\circ}+$ e) y Capitulo $1, n^{\circ}+$, c).

2Véase Rodrigo Inotero: La Cimmunulad Ecominica Caribe-dindinn. Bogotá, 19̣ti. Esta idea no ha perdido su actualidad: cuando las acyociaciones de Cartagena amenazaban fracasar, fuentes del gobierno colombinno insinuaron la posibilidad de que Colombia denunciaria el Tratado de . Iontevileo y promoveria una uatón con Centroamérica y el Caribe, lo que posteriormciue fue desmemido por el conciller. Vease "Is! Espectador" y "El lispacio" de Bergotá, del 25 de albril de aglig. Igualmeme l'enceucla, despućs de retirarse de las negocinciones, ha mitnifestado su interés per Centroamérica y el Caribe; véase "The Economist", del 28 de majo de igóg. 
be: Resulta asi paradojalmente que el acceso preferencial que la Declaración de los Presidentes previó, dentro de un conjunto de otras medidas, como instrumento de perfeccionamiento de la ALALC en su evolución hacia un mercado común, se está enfocando aisladamente como eficaz herramienla para retrotraer a la ALALC a un esquema preferencial.

\section{Implicaciones económicas}

Esbozada la estrategia preferencial en estos términos se plantea un angustioso dilema para los paises de menor desarrollo que participan en e! Acuerdo Subregional Andino, esto es, Bolivia y Ecuador. En efecto, un elemental interrogante que habrán de plantearse - si acaso no se lo han planteado ya- es cuál fórmula es la más conveniente para los intereses económicos que deben promover: si acaso la participación en un acuerdo subregional que les garantiza acceso prefercncial en los mercados de Colombia, Chile y' Perú - paises de mercado insuficiente-, pero que tambićn les impondrá obligaciones muy concretas transcurrido cierto lapso, según se definen en el Acucrdo de Cartagena, y con el agravante de que ya no podrán contar con el mercado de Venezuela como se habia previsto originalmente; o bien la participación en un mecanismo preferencial general que además del acceso a todos los paises de mercado insuriciente les aseguraria un acceso.al mercado de los tres grandes - Argentina, Brasil y México-, sin imponerles obligaciones previamente determinadas que posiblemente se vaýan negociando periódicamente o en todo caso no mayores que las que hoy deben respetar en el marco de la Alalc. Obviamente que la suma de ambas posibilidades seria el ideal a que podrian aspirar en esta situación: sin embargo lo más probable es que la contrapartida que exigirian los tres grandes a cambio del acceso preferencial seria en definitiva incompatible con las obligacioncs que deberán asumir en el marco subregional como contrapartida a los beneficios que recibirán de los demás paises andinos. De aqui resultaria, siempre dentro de lo especulativo, que la situación se plantearia más en términos de opción que de posibilidades de acumulación. La firma del Acuerdo Subregional por parte de Bolivia y Ecuador, asi como las manifestaciones de interés por parte de Paraguay, revelan una primcra opción favorable al criterio subregional; sin embargo ello no rcsuclve el problema de fondo, que alcanzará su máxima dimensión cuando se mate- 
ES T U DIOS INTER NAC:O N A L E S

rialice positivamente la tesis preferencial -lo que todavia está por verse- y se produzca así una disyuntiva que hoy es meramente teórica, y', sobre todo, cuando llegue el momento de cumplir con las obligaciones del acuerdo en materia de desgravación. ¿Prevalecerá entonces la opción subregional, debilitada desde un comienzo por la existencia de amplias cláusulas de denuncia en el Acuerdo?

\section{Implicaciones politicas}

Por otra parte es menester considerar en este análisis un factor que, no por estar hasta ahora subyacente, es menos decisivo: el factor politico. Efectivamente, tanto la doctrina como la práctica han comprobado hasta la saciedad que una situación de dependencia económica va inevitablemente acompañada de una situación de dependencia o de falta de autonomia politica proporcional, salvo que existan mecanismos institucionales que a través de una acción colectiva y solidaria sean capaces de asegurar los resguardos apropiados. $Y$ es aqui donde se produce una diferencia sustancial entre ambas estrategias respecto de los paises de menor desarrollo, pues mientras en el esquema subregional se han concebido organismos politicos y comunitarios que garantizarán la participación equitativa de todos los socios, definiendo con claridad sus respectivos derechos y obligaciones, $y$ por tanto proporcionando el referido resguardo ${ }^{8}$, en un esquema meramente preferencial sc conciben por regla general instituciones absolutamente rudimentarias que tienen por objeto ordenar multilateralmente lo que en sustancia es un conjunto de relaciones bilaterales. En esta última alternativa cada pais sólo tiene cl peso que individualmente pueda producir, con el agravante de que los derechos y obligaciones reciprocos no sc determinan con precisión de antemano sino que se entregan a negociaciones en las cuales siempre predominará el interćs del más fuerte, sin que exista de esta manera la menor posibilidad de resguardo efectivo hacia los más débiles. El fenómeno de la dependencia externa - con todas sus implicancias de satelización- que ha afectado al conjunto de América Latina en sus relaciones con Estados

BInclusive el Acuerdo Subregional prevé cicrtas malcrias, de interćs fundamental para los paises de menor desarrollo, en las cuales no podrán adopiarse decisiones sin el voto favornble de Bolivia o licundor, otorgindose asi a estos paises un derecho de veto para proteger sus intereses. 


\section{Franciscu Orrego / Dilemas en cl Grupo Andino}

Unidos y Europa Occidental, se repetiria asi dentro de la propia América Latina en que los más débiles sufririan los efectos de depender de los más poderosos. En términos económicos -por lo menos en cuanto se reficre a aumentar las exportaciones- es razonable que los paises de menor desarrollo puedan llegar a tener dudas en el momento de optar entre uno $y$ otro esquema; pero en términos politicos, con todas las consecuencias económicas que ellos significan, no pareceria haber alternativa posible.

\section{La solidaridad andina a prueba. Los fundamentos económicos}

El choque de ambass estrategias someterá - y en cierta medida ya ha sometido- a prucba, como lo adelantábamos, la solidaridad interna del grupo andino. Cabe ahora preguntarse si acaso los fundamentos en que descansa la idea de este agrupamiento subregional ofrecen la suficiente firmeza como para resistir incólumes la prueba. La razón de la pregunta es demasiado obvia: si hay una institución en América Latina que se caracteriza por su verbalismo $y$ fragilidad esencial, esa institución es la de la solidaridad latinoamericana, la cual jamás ha podido manifestarse en términos concretos en aquellas circunstancias en que justamente se la ha requerido.

Sin perjuicio de los méritos y fundamentos intrinsecos que puede tener todo proceso de integración económica, en el caso del Grupo Andino se plantearon originalmente dos fundamentos básicos, ambos dentro de una perspectiva latinoamericana: uno de carácter económico, que fue explícito, y' otro de carácter politico, que estuvo implicito. El primero partia de la premisa de que la alalc cumpliría sus objetivos de zona de librc comercio en 1973, tal como lo prevé el Tratado de Montevideo, liberando en esa fecha lo esencial del comercio reciproco; y al mismo tiempo se partia de la premisa de que América Latina contaria con un mercado común en :985, proceso que se iniciaria paulatinamente en 1970 tal como lo previó la Declaración de los Presidentes. Para que los paises de mercado insuficiente y los de menor desarrollo pudieran participar en términos de equidad, competencia efectiva y equilibrio respecto de Argentina, Brasil y México, dentro de ese contexto integrado, se hacía necesario constituir previamente entre ellos una unidad económica viable que asegurara e! logro de esos objetivos; esta unidad viable sería la que proporcionaria el 
ESTUDIOS : NTER N A C I O N A LES

acuerdo subregional mediante un mercado ampliado, una tarifa cxterior común y un conjunto de politicas coordinadas, principalmente en el campo industrial. Sobre la base de estas premisas fuc que Colombia y Chile presionaron durante largo tiempo para que se aceptara el plazo de seis años como máximo tolerable para el pleno funcionamiento del acucrdo, pues de lo contrario ya seria tarde para participar equilibradamente en el mercado común latinoamericano".

Pero lamentablemente para América Latina, ambas premisas resultaron fa!sas, siendo hoy claro y definitivo que no habrá zona de libre comercio en 1973 y, por lo que se proyecta, tampoco habrá mercado común en 1985. Por lo tanto este fundamento económico del Grupo Andino, que le daba tonalidades de urgencia y aceleración, ya no ofrece ninguna consistencia en lo inmediato, consecuencia de lo cual ha sido que el Acuerdo de Cartagena recoja un plazo de once años para su pieno funcionamiento reconociendo asi que el mercado común latinoamericano ya no es tan inminente. De ahi entonces que tampoco resulte posible basar la solidaridad interna en la necesidad de protegerse rápidamente de una competencia de Argentina, Brasil y'México ${ }^{10}$. Lo expuesto, repetimos, no prejuzga acerca de los méritos intrínsecos del acuerdo subrcgional.

\section{Los fundamen los politicos}

En lo que toca al segundo fundamento básico, el de carácter politico, la realidad nos lleva a conclusiones semejantes. Si bien nunca se puso énfasis en este aspecto, resultaba demasiado claro que habia un común denominador politico entre los gobicrnos de Belaúnde, Frci, Leoni y' Lleras Restrepo, no quizás hasta el punto de constituir "bloques" en América Latina, como fue el decimonónico epiteto con que algunos lo calificaron en un comienzo y que rememora la política del equilibrio de potencias

\footnotetext{
9 Vénse en particular la enrta que el Presidente de Colombia dirigió, el + de abril de 1968 , a sus colcyas presidentes de los paises del Grupo Andino, donde tiesarrolta in extenso cstos argumenos. Este documento fuc amplinmente comentado por la prensn.

${ }^{10} \mathrm{La}$ posición de Venezuela es al respecto to sulicicatiemente demostrativa pucs no sólo no adhirió al acucrdo subregiona! sino que, además, planten como alternativa la revialización de la alalc, buscando de esta manera proteger su industria de la competencia subregiolla! y, por anto, asumiendo de que no existe ricsgo de una competencia por parte de Argent:na, Brasily y México en cl marco más amplio de la aluze.
} 
practicada en Europa hasta la Primera Guerra Mundialit, pero si lo suficientemente coherente como para desarrollar acciones comunes de cierta envergadura, coherencia que naturalmente se fortalecia al contrastarse con los gobiernos militares de Argentina y Brasil. Ecuador se encontraba en ese momento en un proceso de reformas constitucionales que en ningún caso lo alejaba de ese común denominador. Esta circunstancia netamente política, acompañada del hecho de que todos estos paises habian mantenido una posición más o menos homogénea en el marco de la ALALC dada su condición de paises de mercado insuficiente o de menor desarrollo, produjo el segundo fundamento básico que dio origen a la idea del Grupo Andino, reajustando incluso la tesis original de Colombia de constituir una Comunidad Económica Caribe-Andina, a la que se hizo referencia anteriormente.

La incorporación de Bolivia al Grupo Andino ${ }^{2}$ introdujo la primera variación en el común denominador politico, pues se trataba de un gobierno que no participaba plenamente de las caracteristicas generales de los demás; no significaba ello que se entrabaria la marcha de las acciones emprendidas sino simplemente que lo que hasta entonces podia calificarse de politicamente homogéneo ya adquiría un carácter menos homogéneo, acercándose a lo heterogéneo. Esta ligera variación se justificaba plenamente a la luz de razones económicas impuestas por la vecindad, de razones de justicia en cuanto se procuraba atender la situación de los paises de menor desarrollo $y$, sobre todo, de razones estratégicas dentro de la politica general de la ALALC. Efectivamente la incorporación de Bolivia permitia que la idea subregional fuera mayoritaria en la ALALC - seis paises sobre once-, lo que en esos momentos era particularmente importante debido a las resistencias que ella habia despertado en la ALALC, hasta tal punto que casi fracasó en la segunda reunión del Consejo de Ministros como muchos de los demás mandatos presidenciales — habiendo sido objeto de un lenguaje hostil poco común en la habitualmente diplomática

${ }^{12}$ Esta imputación fue terminantemente desntentida por una Declaración Oncial del Ministerio de Relaciones Exteriores de Chile, del 26 de julio de 1966 . Véanse tambičn las declaraciones del Dr. Joaquín Vailejo, negociador por Colombia, en el diario "El Tiempo" de Bogotá. del $: 7$ de julio de $: 967$.

22 Bolivia adhirió a la Declaración de Bogutá el 18 de agosto de 9967. 
ALAI_C- ${ }^{13}$; hay quienes inclusive interpretan que la idea subregional sólo se salvó en esta reunión gracias al desacuerdo general que hubo en torno a todas las demás materias encomendadas por los presidentes y que, para no dar la impresión de un colapso general, se habria decidido superar las diferencias acerca de lo subregional e instrumentar aunque sólo fuera esta decisión presidencial. Sea como fuere, la participación de Bolivia, acompañada de la posición favorable que manifestaron Paraguay y Uruguay como paises eventualmente interesados, fue un factor determinante para recibir la venia de la ALALc. Bienvenida entonces la flexibilidad politica que permitió el acceso de Bolivia al acuerdo subregional ${ }^{14}$.

Muy diferentes en cambio fueron las implicaciones políticas que se derivaron de la situación acaecida en el Perú cuando cayó el Gobierno de Belaúnde y asumió el poder la junta militar. En ese momento se quebró irremediablemente la homogeneidad politica del Grupo Andino, transformándose en un agrupamiento tan heterogéneo desde este punto dé vista como lo puede ser la propia Alalc. Esta vez sí se entrabó la marcha de las negociaciones, pues Venezuela, en aplicación de la Doctrina Bètancourt, se negaba a sentarse a negociar con el nuevo gobierno peruano, razón por la cual las reuniones de la Comisión Mixta fueron postergadas en sucesivas ocasiones; para superar esta situación los cancilleres de Colombia y Ecuador formularon una doctrina en virtud de la cual el participar en reuniones técnicas no implica un reconocimiento tácito de nuevos gobiernos ${ }^{15}$. Los cambios constitucionales de gobierno que entretanto ocurrieron en Ecuador $y$ Venezuela significaron una demora adicional en este largo proceso, pues ambos solicitaron plazos para estudiar los proyectos.

\footnotetext{
${ }^{13}$ Véase por ejemplo el proyecto de resolución presentado por la Delegación de Argentina proponiendo una reglamentacion restrictiva de ins acuerdos subregionales. Doc. ALLc/C.r. II/P'l-E/dc. 25.22 de agostos ig67.

${ }^{14}$ Cabe observar que como consecuencia del retiro de Venezuela, se ha vuelto a la situación original en el marco de la Alalc, esto es, los paises participantes en el acucrdo subregional han quedado en minoria respecto a los paises no participantes; sin embargo esta situación no reviste ahora la gravedad que originalmentc tuvo, pues una vez aprobadas las normas sobre acuerdos subregionales por parte de la Asociación se ha facilitado enormemente el camino para la idea subregional.

${ }^{13}$ Declaración yonjunta de los cancilleres de Colombia $y$ Ecuador de octubrc de 1968 , publicada en el diario "El Espectador" de Bogotá el 28 de octubre de tg68.
} 
El hecho concreto es que ai no darse hoy dia en el Grupo Andino un común denominador politico -que le sirvió originalmente de fundamento básico- tampoco podrá basarse en este factor la solidaridad interna de la subregión. En ausencia de fundamento económico extcrno y de fundamento político en los cuales basar una necesaria solidaridad, en los términos que se han expuesto, cabe preguntarse cuál podria ser esa base. La única base que es posible imaginar a esta altura del proceso es aquella que derive del convencimiento de que la integración subregional es válida, necesaria y viable per se, en función de sus propios méritos y no en función de fenómenos externos a la subregión como en cierto modo se habia venido planteando su justificación. Sólo cuando se llegue al convencimicnto intimo y definitivo de que la ampliación de los mercados, la liberación comercial y la coordinación de politicas económicas al nivel subregional es la llave indispensable para ascgurar una expansión industrial, una racionalización económica y un crecimiento sostenido podrá el Grupo Andino readquirir una cohesión interna que le permita actuar solidariamente frente a estrategias contradictorias en definitiva. Se trata entonces de que la integración subregional opere sobre la base de estimulos internos $y^{\prime}$ no constituya solamente una reacción frente a problemas externos; estos últimos sin duda mantendrán una importancia relativa hasta el momento en que las perspectivas de un mercado común latinoamericano rccobren su vigencia, razón por la cual tampoco debieran perderse de visın, pero no constiluy'en hoy dia un estímulo lo suficientementc constante como para permitir que la idea subregional se fundamente solamente en cllos. El retiro de Venezuela nuevamente habla por si solo.

\section{Dificultades adicionales}

Desafortunadamente, esta solidaridad del convencimiento tambièn se ha encontrado y puede seguir encontrándose con serios obstáculos, a pesar de los sobrehumanos esfuerzos que han venido desplegando los representantes personales del Presidente Lleras Restrcpo, señores Jorge Valencia Jaramillo y Felipe Salazar Santos, quienes recorrieron una y otra vez los paises de la subregión en busca de un entendimiento. Aparte de los hipoté- 
ESTUDIOS I XTER NACIONALES

ticos problemas que ya se analizaron respecto de Bolivia y Ecuador, surgen en este punto los planteados por Perú y Venezuela y que, en delinitiva, condujeron a la marginación de este último pais y' a la dubitativa posición que mantuvo el primero durante el curso de las negociaciones de Cartagena. La argumentación central que plantearon ambos gobiernos fue que la integración subregional no debia afectar las industrias existentes, esto es, debia referirse solamente a las producciones futuras, salvo excepciones que podrian canalizarse a travćs de acuerdos de complcmentación o programas sectoriales de desarrollo industrial. Dicha posición en realidad no innovaba en nada respecto de lo que ha sido la práctica de las negociaciones de la ALALC pues los gobiernos, salvo rara excepción, jamás han otorgado concesiones respecto de productos competitivos con sus respectivas producciones nacionales, e incluso en casos en que por error dichas concesiones se han otorgado luego han sido retiradas sin protesta por partc de los demás gobiernos, que crean asi un precedente para acogerse eventualmente a él en caso necesario aun cuando muchas veces esta lórmula signifique violaciones del Tratado, desamparo a los exportadores u otras irrcgularidades. Ha habido, pues, una plena protección a las industrias existentes, que es lo que Perú y Venezuela procuraban obtener en el acuerdo subregional.

Repetir esta fórmula al nivel andino habia sido completamente estéril pues bien podria lograrse lo mismo en la alalc sin necesidad de crear un mecanismo subregional; por otra parte los acuerdos de complementación de todas maneras deberán tramitarse vía Alalc pues asi lo dispone expresamente el régimen que regula los acuerdos subregionales, con lo cual nada justificaria tampoco un mecanismo subregional; $y$ por último si el acucrdo subregiona! se fucra a limitar solamente a produccioneș futuras también ello podria lograrse a través de los acuerdos de complementación, cuya rcglamentación autoriza mecanismos como la tarifa exterior común, la coordinación de políticas, localización de plantas y oțros, sin que tampoco les sca aplicable el juego irrestricto de la cláusula de la anación más favorccida ${ }^{16}$. La integración subregional sólo puede concebirse como un proceso general y completo, que sólo contemple excepciones muy delerminadas y con plazos muy precisos; de lo contrario nada se ha adelantado. Afortunadamente así lo entendió el Acuerdo de Cartagena.

${ }^{10}$ Véase la reglamentación estableciola por la Resnlución 99 de la Confercncia de AINLC. 
La posición que se ha descrito de Perú y Venezuela demuestra que hasta ahora la solidaridad del convencimiento tampoco es una posibilidad muy cierta. Venezuela definitivamente no adhirió a esta solidaridad retirándose de las negociaciones de Cartagena y abandonando un esquema subregional dentro del cual temía verse afectada por una competencia efectiva. Este desenlace ya podia preverse con anticipación a la última rueda de negociaciones, pues no obstante que el nuevo Presidente de Venezuela anúnció un "vigoroso impulso" a la integración latinoamericana por parte de su gobierno, agregó que tales fórmulas no debian poner "en peligro lo ya logrado hasta ahora, sino que a base de la protección de lo existente, es decir, de los impulsos dados a nuestro desarrollo inciustrial, abran nuevos caminos..." la posición de FEDECamaras, la asociación industrial que tanto combatió los proyectos de integración subregional. En la búsqueda de una protección a su industria Venezuela probablemente adherirá en definitiva a la tesis preferencial en el marco de la ALALC - o en el mejor de los casos a la mantención de la ALALC en sus condiciones actuales- pero no podrá procurar seriamente la "revitalización" de la Alalc pues la única manera de lograrlo seria acelerando el proceso de integración, $y$ por tanto la competencia regional, que es justamente de lo que trata de precaverse. La victoria de FEDECAMARAs se transformará entonces, en corto plazo, en una victoria pirrica pues se traducirá finalmente en que Venezuela tenga cada dia menos acceso a otros mercados en expansión.

Distinto fue, en cambio, el-desenlace en lo que respecta a la posición del Perú, pais que finalmente suscribió el acuerdo subregional a pesar de la actitud dubitativa que mantuvo en el curso de las negociaciones de Cartagena: Sin embargo ¿̇ignificará este hecho que Perú ha abandonado definitivamente la tesis proteccionista que compartió con Venezuela y que también recibió el apoyo de sus sectores empresariales? A esta altura del proceso no puede responderse seriamente ni en un sentido ni en otro, debiëndose a lo más indicar algunos antecedentes dignos de tener en consideráción. El primer hecho que cabe notar es que la adhesión del Perú fue frutö de una transacción en lo que respecta a la extensión y amplitud de la protección arancelaria que cada pais será autorizado a mantener, utilizan-

17 Véanse las Deciaraciones del Presidente Rafael Caldera, publicadas en el diario "El Corren" de . ledellin, cl to de marzo de igbig. 
E S T U DIOS I N TER N A C IONA L E S

do a este efecto el mecanismo de listas de excepción en las cuales se incluirán productos que no serán afectados por el programa de liberación; asi, Perú podrá exceptuar hasta $45^{\circ}$ item de NABALALC en contraposición a Colombia.y Chile que sólo podrán exceptuar 250 item. Si bien es cierto que el número de excepciones se nivelará respecto de los tres paises en conformidad al calendario que especifica el Acuerdo, no es menos cierto que este mecanismo diferenciado significa un nivel de protecciơn más amplio en beneficio del Perú. De aqui resulta, entonces, que la tesis proteccionista del Perú ha subsistido, por lo menos parcialmente, en el Acuerdo de Cartagena y en un grado aceptable para el sector privado de este pais, el cual estuvo fuertemente representado en la delegación que asistió a las negociaciones de Cartagena. Puede apreciarse a la vez que la posición "preferencialista" del Perú en la ALALC ${ }^{2-}$ guarda armonia con su politica en lo subregional pues ambas procuran una adecuada protección a la industria existente; en tal sentido poco se diferencia de la posición venezolana.

En el caso del Perú hay también un factor politico adicional que debe tomarse en consideración, por lo menos desde un punto de vista especulativo. Para fortalecer su posición en el conflicto de la IPC - agravado aún más por el conflicto pesquero y los que eventualmente deriven de la reforma agraria - Perú necesitaba vivamente de una expresión de solidaridad latinoamericana que, como se indicó, no es fácil de conseguir. Dicha expresión de solidaridad fue otorgada en términos amplios por las reuniones de cecla, celebradas en Viña del Mar entre el 7 y el 17 de mayo pasado, expresión que se reflejó tanto en el discurso inaugural del Presidente Frei como en el Consenso de Viña del Mar al reafirmarse la soberania sobre las riquezas básicas. Perú recibió asi la necesaria solidaridad; pero para recibir solidaridad también hay que darla y, siempre dentro de lo especulativo, ¿no pudo acaso haberle llegado el turno al Perú con ocasión de la firma del Acuerdo Subregional? Por otra parte la, situación politica interna del Perú y el mayor grado de solidaridad que el gobierno ha logrado con motivo de los referidos conflictos, bien pudo haber influido en que el sector privado moderara sus criticas respecto de la integración subregional y se allanara a una transacción en Cartagena, a diferencia de lo ocurrido con el sector privado venezolano. Pero ¿̇subsistirán estas consideraciones de solidaridad una vez superadas las dificultades actuales del Perú?

19 V'́asc exposición del Embajador X.Lax de ia Fuentc, citada en la nota 5 supra. 
Lo expuesto permite llegar a una conclusión provisional y es ella que la tesis proteccionista aún subsiste en el seno de la subregión, autorizada parcialmente por e! propio Acuerdo, con todas las vinculaciones obvias que ella tiene en la tesis "preferencial" en el marco de la aLAlc. El momento de prueba vendrá, al igual que en el caso de los paises de menor desarrollo, cuando Perú deba dar cumplimiento a los compromisos de desgravación impuestos por el acuerdo subregional; si la transacción de Cartagcna no resulta suficiente dentro de las perspectivas proteccionistas prevalecientes es posible que Perú se incline delinitivamente por la estrategia preferencial en el marco de la aLAlc, que le daria plena seguridad de protección a sus industrias existentes, abandonando el esquema subregional basado en la competencia efectiva y reencontrándose asi con la estrategia venezolana. Es menester no olvidar que en ausencia de una solidaridad real los paises tienden a guiarse por sus intereses inmediatos.

\section{Hacia una estrategia realista}

Este conjunto de problemas llevó at que dentro del propin Crupo Andino se enfocaran las estralegias con mayor realismo. Asi se hicicron todos los esfuerzos posibles para que el proceso pudiera iniciarse con la participación de los seis paises signatarios de la Declaración de Bogotá; pero ante la evidencia de que estos esfucrzos fracasarian sc acogió la estrategia de iniciarlo sólo entre aquellos paises que estaban dispuestos a firmar el proyecto de Cartagena de 1968 , aceptando algunas modificaciones transaccionales - como las que efectivamente se concedieron al Perú y' en un momento se ofrecieron a Venezuela - pero sin esperar a que todos otorgaran su conformidad. En esta última alternativa incluso sc procuró dejar la puerta abierta para permitir el acceso de los países reticentes en la medida en que se fueran convenciendo de la necesidad de la integración subregional ${ }^{19}$. Cuando se inició la última reunión de Cartagena sólo Bolivia, Colombia y Chile se habian declarado dispuestos a firmar el proyecto de

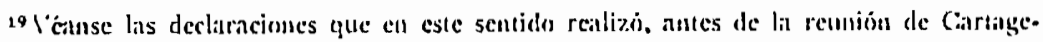

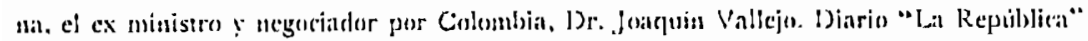

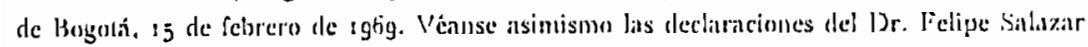

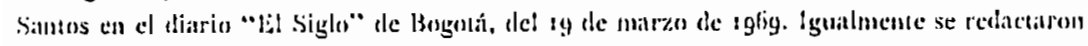

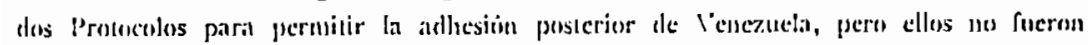

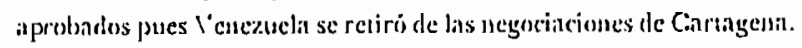


ESTUDIOS INTER NA CIONALE S

1968, pero, a pesar de las dudas planteadas sobre la viabilidad de una integración subregional entre estos tres paises únicamente, se estaba de acuerdo en iniciar el proceso de todos modos. En esta estrategia influyó decisivamente la urgencia impuesta por los plazos, pues asi como los cambios de gobierno de Ecuador y Venezuela demoraron las negociaciones en varios meses, los cambios de gobierno que deberán ocurrir en Colombia y Chile en I 970 bien podrian haber significado demoras adicionales si acaso el acuerdo no se hubiera firmado en el curso de este año. También sc corria el riesgo de transformar este esfuerzo en un csfuerzo tardio si acaso no se procedia con prontitud ${ }^{20 i}$.

Hoy comienza a discutirse si acaso una integración subregional sin Venezuela es viable o al menos si ella producirá frutos dignos del esfuerzo. Pero suponiendo que lo fuera todavia subsisten algunos problemas serios. Elacuacuerdo subregional ha sido concebido dentro del marco del Tratado de Montevideo como un desarrollo especial del mismo, estando asi amparado por ese techo juridico; pero si el Tratado de Montevideo resultara sustancialmente reformado en caso de acogersc la tesis preferencial para la Alalc bien pudicra correrse el riesgo de privar al acuerdo subregional del marco básico bajo el cual se cobija, lo que produciria, entre muchas otras consecuencias, una larga demora adicional, pues el acuerdo deberia ser sometido a ratificación y aprobación parlamentaria en cada pais miembro sin poder entrar en vigor a través del amparo del Tratado de Montevideo como hoy' se prevé. Al mismo tiempo se abriria en los parlamentos un debate interminable. Pero aun cuando el techo juridico del Tratado de Montevideo subsista, a pesar de algunas eventuales modificaciones, el acoger la tesis preferencial plantearia un serio problema a los paises miembros del GATT; el waiver otorgado a la ALALC por el GATT se fundamenta en el articulo xxiv del Convenio de este último, que prevé la zona de libre comercio como una excepción a la cláusula de la nación más favorecida, autorización que se cxtenderia al Grupo Andino por estar amparado por el Tratado de Montevideo; pero si se abandona la zona de libre comercio y' se implanta un régimen preferencial caduca la autorización basada en el articulo xily, quedando por tanto el Grupo Andino desprovisto de la venia del GATT para continuar adelante. Naturalmente

\footnotetext{
'20 Esta opinión tambien fue señalada por el Dr. Joaquin Vallejo en las referidas declaraciones.
} 
que siempre será posible una negociación con el GATT, que de todas naneras deberia realizarse para rcgresar al régimen preferencial; pero seria la demostración ante el mundo de cuán poco se respetan los calendarios y compromisos de integración en América Latina.

\section{Un nuevo común denominador}

En todo caso, mientras más se accrquen las soluciones buscadas a la realidad de los hechos, mayores serán sus probabilidades de exito. Asi como en el marco de la integración general de América Latina se ha ido abandonando poco a poco la concepción bolivariana de esperar la presencia de todos, y asi como dentro de la propia Alalc se reconoció que no todos debian proceder con la misma velocidad —autorizándose en consecuencia los acuerdos subrcgionales más acelerados- quizás cabria hacer lo propio dentro del Grupo Andino concibiendo diferentes velocidades para diferentes intereses. Dentro del marco de la Comunidad Económica Europea sc ha ensayado con éxito esta compatibilización de intereses: la Comunidad representa el ritmo más lento pero dentro de ella sc autoriza un mecanismo más acclerado que es el del Bexéux, e inclusive dentro de cste último se autoriza un mecanismo todavia más acelerado que es el de la Unión Económica Belga-Luxemburguesa (UEBL) ${ }^{21}$

Guardando las proporciones y diferencias de objetivos bien pudo haberse pensado en la ALALC como el ritmo más lento, en el Grupo Andino como mecanismo más acelerado con la participación de los scis paises signatarios de la Declaración de Bogotá y', denrro de este último, en una Córmula más acelerada todavia que permitiera satisfacer las aspiraciones de quienes asi lo desearan, que a la fecha de iniciarsc las últimas negociaciones de Caragena eran Bolivia, Colombia y Chilc. Así como el régimen especial que se concibió para los paises de menor desarrollo cconómico relativo constituye una aplicación concreta del principio del diferentc ritmo para-difcrentes intereses, ¿no pudo acaso haberse previsto otro ritmo para aquelios intercses que estaban dispuestos a ir más allá que la ALALC pero no tan lejos como lo deseaban Colombia y Chile? Quizás esta aproximación rcalista hubiera permitido encontrar el común denominador de intereses

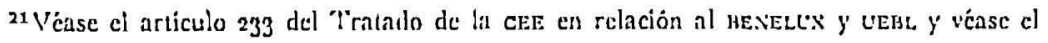
artículo $94 \mathrm{del}$ "l'ratado del hevelux en relación a la uest. 
ESTUDIOS INTERNACIONALES

cuya búsqueda resultó infructuosa durante el largo proceso de negociaciones subregionales; quizás hubicra permitido la adhesión de Venezuela, cuya importancia politica y cconómica no debiera subestimarse, y' al mismo tiempo hubiera cvitado las complicaciones que vendrán respecto cic la Corporación Andina de Fomento, de la cual será con certeza excluida Venczucla; y quizás también hubiera permitido la adhesión sin reservas mentales de Ecuador y Perú que, como se indicó, puedic ser fuente eventua! de futuras dificultades. Este conjunto de factores habria a su vez evitado que el ritmo de la integración continue midiéndose de acuerdo al compás más lento, fenomeno al cual no escapa el acuerdo de Cartagena -particularmente en materia de plazos- aunque obviamente con menor intensidad que el caso de la alas.c.

El momento idcal para proceder a la institucionalización de ese esqucma de las diferentes velocidades, que a la larga a todos hubiera convenido, fue obviamente el de las últimas negociaciones de Cartagena. Lamentablemente no ocurrio asi, de dond: pueden incluso derivar complicaciones en lo que respecta a la declaración de compatibilidad - -particularmente con la Resolución 2o3- que deben efectuar los órganos de la Alalc. Sin cmbargo, tal es una solución que no debc perderse de vista por parte de los responsables de la conducción del proceso subregional y que, de ser seriamente considerada, podría llevar a pensar en alguná fórmula de asociación especial para Venezuela con el Grupo Andino - que le ofreciera la posibilidad de avanzal mảs que lo que permitc alalc pero no tanto como aspirat el acucrio subregional- c inclusive, llegado el caso, a pensar en las modificaciones pertinentes al acuerdo para cuyo efecto los órganos subregionales han sido dotados de las competencias adecuadas.

A modo de conclusión cabe simplemente indicar que muchas de las interrogantes y de los problemas planteados se irán contestando en la medida en que el acucrdo subregiona! se vaya acercando a los plazos que prevé su calendario. Denlás esıi decir quc el grupo andino deberá redoblar sus esfuerzos en la busqueda de un común denominador y de una solidaridad interna que no se base en hechos circunstanciales y pasajeros, pues de ello dependerá no sólo la suerte del propio acuerdo subregional sino que ademais el fuluro de la Alatc, desde el momento en que una posición honogénca de cstos paises será determinante para resolver si acaso la asociación persevera en la consecución de sus actuales objetivos o, como algunos piensan, retroceda hacia meras fórmulas preferenciales que 


\section{Francisco Orrego / Dilemas en el Grupo Andino}

ubicarian a Amćrica Latina en una fasc preintegrativa de escasas proyecciones. Ello a su vez exigirá de una auténtica y cficiente definiciön política, llena de contenido y realismo, que supere definitivamente los cstérilcs formalismos que en gran medida son los responsables de este dramático conjunto de dilemas.

Julio de 1969 